\title{
The history of telescopes and binoculars: an engineering perspective
}

John Greivenkamp, David Steed

John E. Greivenkamp, David L. Steed, "The history of telescopes and binoculars: an engineering perspective," Proc. SPIE 8129, Novel Optical Systems Design and Optimization XIV, 812902 (10 September 2011); doi: 10.1117/12.904614

SPIE Event: SPIE Optical Engineering + Applications, 2011, San Diego, California, United States 


\title{
The History of Telescopes and Binoculars: An Engineering Perspective
}

\author{
John E. Greivenkamp* and David L. Steed \\ College of Optical Sciences, University of Arizona, 1630 E. University Blvd, Tucson, AZ 85721
}

\begin{abstract}
The design of the refracting telescope advanced rapidly following its invention in 1608, reaching its modern configuration in about a century. Even though the development of binoculars began almost simultaneously, nearly three hundred years elapsed before practical prismatic binoculars became available. The impediments to practical binoculars were not only in optical design, but in mechanical design, manufacturing, and materials. This paper will document the history of telescopes and binoculars from an engineering perspective looking at the evolution of basic optical system layout as well as some of the mechanical issues faced. This development will be illuminated using examples from the Museum of Optics at the College of Optical Sciences at the University of Arizona.
\end{abstract}

Keywords: Binoculars, Telescopes, History of Optics, Antique Optics, Optical Design, Optical Instrumentation

\section{INTRODUCTION}

The development of practical handheld refracting telescopes and binoculars is much more than the story of optical design. It must be told in conjunction with advances in mechanical design, manufacturing technology and materials development. A strong argument can be made that the path to modern optical instrumentation is as dependent on the availability of precision brass tubing in the mid-1700s as it is on the innovations in the optical designs of the instruments. Because of this, collections of antique optical instruments are often referred to as "glass and brass."

While the most obvious differences between handheld telescopes and binoculars and astronomical telescopes are the diameters of the objective lenses and the system size, the more significant difference may be that handheld telescopes and binoculars were produced in far greater numbers. This trend continues to the present. These instruments are mostly intended for terrestrial applications and produce erect images. The early uses were primarily nautical and military; consumer use including sports and theater followed later. These telescopes and binoculars were not one-off instruments and the design and engineering had to be consistent with a production environment.

Hans Lipperhay of the Netherlands is credited with inventing the telescope in 1608. His patent application was followed a week later with a request from the examining committee "to ascertain ... whether he could improve it so that one could look through it with both eyes" [1]. Within several months, Lipperhay constructed and demonstrated this first pair of binoculars. The development of telescopes and binoculars began almost simultaneously, yet the telescope reached its modern design configuration in about a century while it took almost three hundred years for the modern form of prismatic binoculars to become practical. This delay was due to the fact that binoculars are more than just two telescopes. There are significant engineering challenges in the requirements that the optical axes of the two telescopes be parallel or collimated and that the two magnifications must be matched [2]. The ability to adjust the interpupillary separation to match that of the user is another important design feature.

This paper will document the development of handheld telescopes and binoculars using examples from the Museum of Optics at the College of Optical Sciences at the University of Arizona.

*greiven@arizona.eduｗww.optics.arizona.edu/museum

Novel Optical Systems Design and Optimization XIV, edited by R. John Koshel,

G. Groot Gregory, Proc. of SPIE Vol. 8129, 812902 - (C) 2011 SPIE

CCC code: $0277-786 \mathrm{X} / 11 / \$ 18 \cdot$ doi: $10.1117 / 12.904614$

Proc. of SPIE Vol. 8129 812902-1 


\section{REFRACTING TELESCOPES}

Following the demonstration of the Galilean or Dutch form of the telescope (a positive focal length objective lens with a negative focal length eye lens) in 1608, the telescope evolved rapidly. Some of the important dates in the development of the refracting telescope are [1, 3-8]:

- 1611: proposal by Johannes Kepler of the astronomical telescope consisting of two positive lenses.

- 1617: first recorded construction of a Keplerian telescope by Christoph Scheiner

- Circa 1625: introduction of a single erecting lens in the Keplerian telescope to produce an erect image by Christoph Scheiner.

- 1645: Anton Maria Schyrle de Rheita used a two element erecting couplet to produce a practical terrestrial telescope with an erect image and acceptable magnification and field of view.

- 1662: two-lens eyepiece incorporating both an eye lens and a field lens was invented by Christian Huygens. This combination of a Schyrle erecting system and a Huygens eyepiece represents the basic optical system layout of the terrestrial or relayed-Keplerian telescope that survives to this day. Figure 1 schematically illustrates the evolution of the refracting telescope. In most situations, all of the optical elements except the objective lens are mounted with fixed spacing in the last draw or eye draw of the telescope. Additional improvements that were incorporated into the design are a field stop placed between the two elements of the Huygens eyepiece, and a glare stop at the intermediate pupil location between the two erecting lenses. The intermediate pupil is the image of the objective lens aperture formed by the first erecting lens.

Telescopes incorporating the Schyrle erecting system (three-lens eyepiece) were into production and available in the last half of the 1600s. There is some evidence that the four-lens eyepiece was in use in the late 1600s, however it fell out of favor until the mid-1700s [7]. At that time, telescopes using Schyrle-Huygens erecting systems with both four and fivelens eyepieces were in production. While there were improvements to follow, most notably the achromatic objective in the mid-1700s, the modern design form of the terrestrial refracting telescope was firmly established by this time.

\subsection{Chromatic Aberration and the Achromatic Doublet}

The primary limitation of the image quality that was produced with early telescopes was chromatic aberration of the objective lens. Because of the color dispersion of the glass in a simple objective lens, different wavelengths have different focal lengths and are brought to focus at different distances. The longitudinal blur associated with chromatic aberration limits the angular resolution of the telescope. For a given focal length lens and glass type, the only method to reduce the blur was to use a lens with a small diameter or to use an aperture to reduce the effective lens diameter. This situation is shown in Figure 2. In the early 1700s, it was believed that chromatic aberration was fundamental and could not be corrected. There was a tradeoff between resolution and light collecting ability, and most handheld telescopes of this era had very small objective lenses, often with an effective aperture diameter of 10-15 mm. An example of a preachromatic telescope with a Schyrle erecting system is shown in Figure 3.

An interesting and unusual configuration that occurred with pre-achromatic telescopes is the reverse taper telescope. The angular field of view largely determines the required diameters of the erecting lenses and especially the field lens. In higher magnification telescopes, the objective lens could be smaller than the lenses in the eye draw. The objective end of the telescope is smaller in diameter than the eyepiece end. A reverse taper telescope is shown in Figure 4.

Achromatic objectives correct chromatic aberration by combining a positive lens made from a low-dispersion glass with a negative lens made from a high-dispersion glass. The original inventor of the achromatic objective is Chester Moor Hall, a barrister in London [9]. In 1733, he commissioned two different opticians, Edward Scarlett and James Mann, to each make one of the lens elements. By chance, both opticians subcontracted the work to the same man, George Bass. Chester Moor Hall then continued to keep his invention secret. Around 1750, Bass told optician John Dollond about the achromatic lens he had made. Dollond's son, Peter, saw the commercial advantages and once they had made test lenses, patented the invention in 1758. Chester Moor Hall twice attempted to challenge the patent. He lost his case on the grounds that the person who should profit by the invention is the one who benefits the public by it, not one who keeps it locked in his desk drawer. This was a landmark decision in patent law that remains in place to this day. 
The achromatic doublet was a significant optical improvement for telescopes. It allows for improved resolution with much larger objective lenses and more light-gathering capability. Most handheld telescopes could have objective lenses with diameters of 25-50 mm or larger. Dollond went on to become the dominant manufacturer of telescopes in the late 1700 s and early 1800s. The name "Dollond" became a synonym for a telescope.

\section{Scheiner Erecting System}

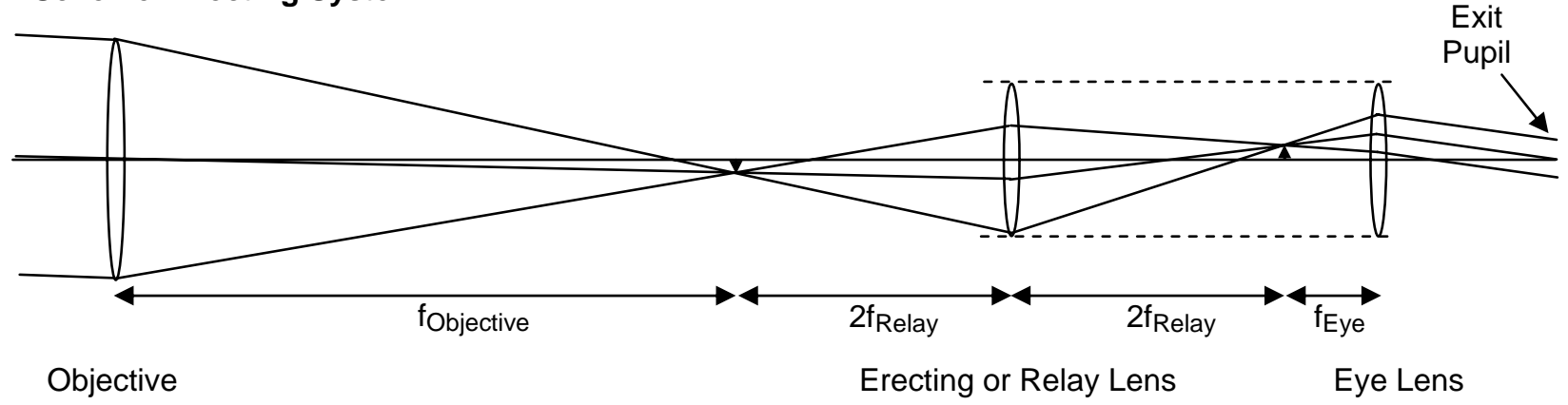

\section{Schyrle Erecting System}

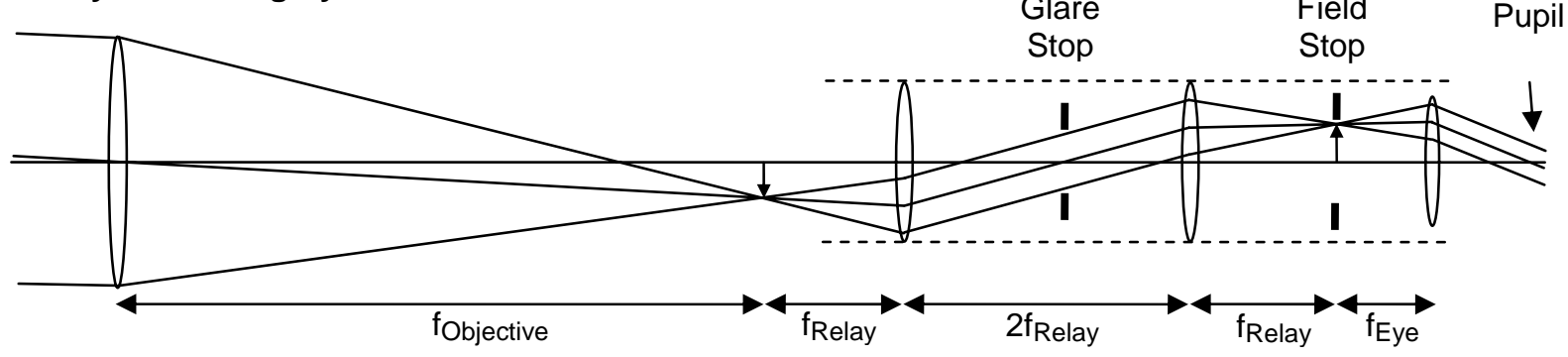

Objective

\section{Schyrle Erecting System with Huygens Eyepiece}

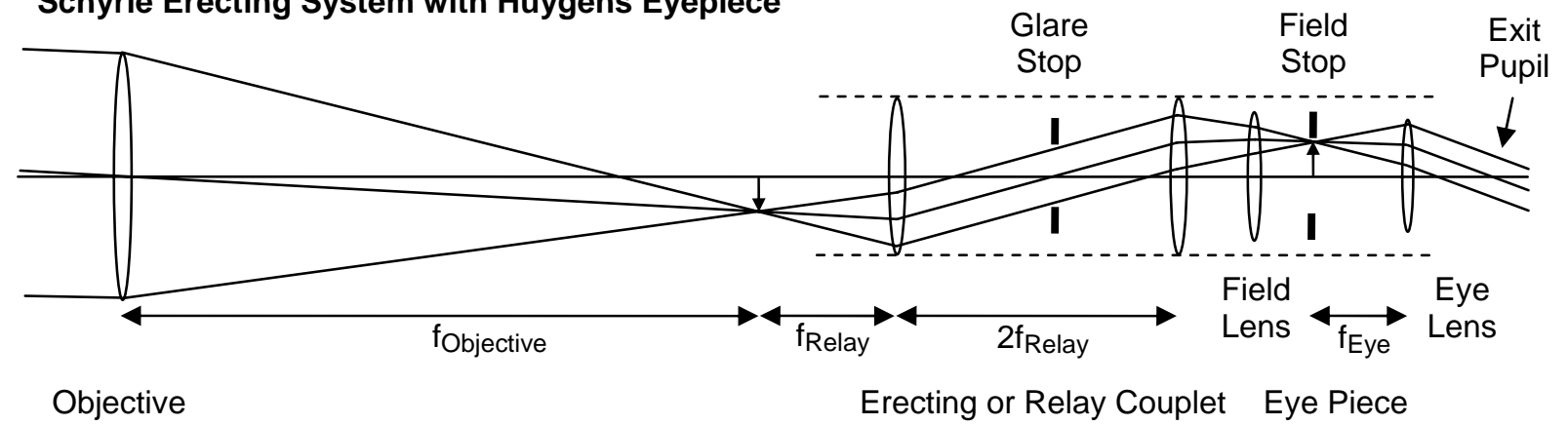

Figure 1. The evolution of the design of the terrestrial or relayed-Keplerian telescope. The separation between the elements in the erecting couplet was often twice the lens focal length, but this is not required. The Schyrle erecting system is often referred to as a three-lens eyepiece, and the Schyrle-Huygens erecting system as a four-lens eyepiece. In some telescopes, an additional field lens was inserted at or near the first intermediate image resulting in a five-lens eyepiece. 


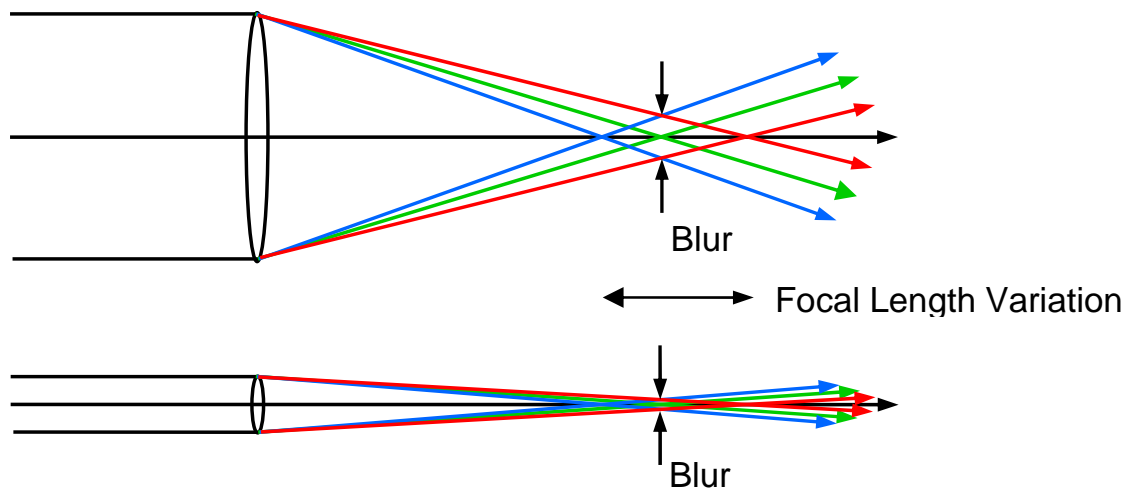

Figure 2. The blur associated with longitudinal chromatic aberration. The angular resolution of the system is improved by reducing the diameter of the lens aperture. The chromatic variation of focal length does not change with aperture diameter.

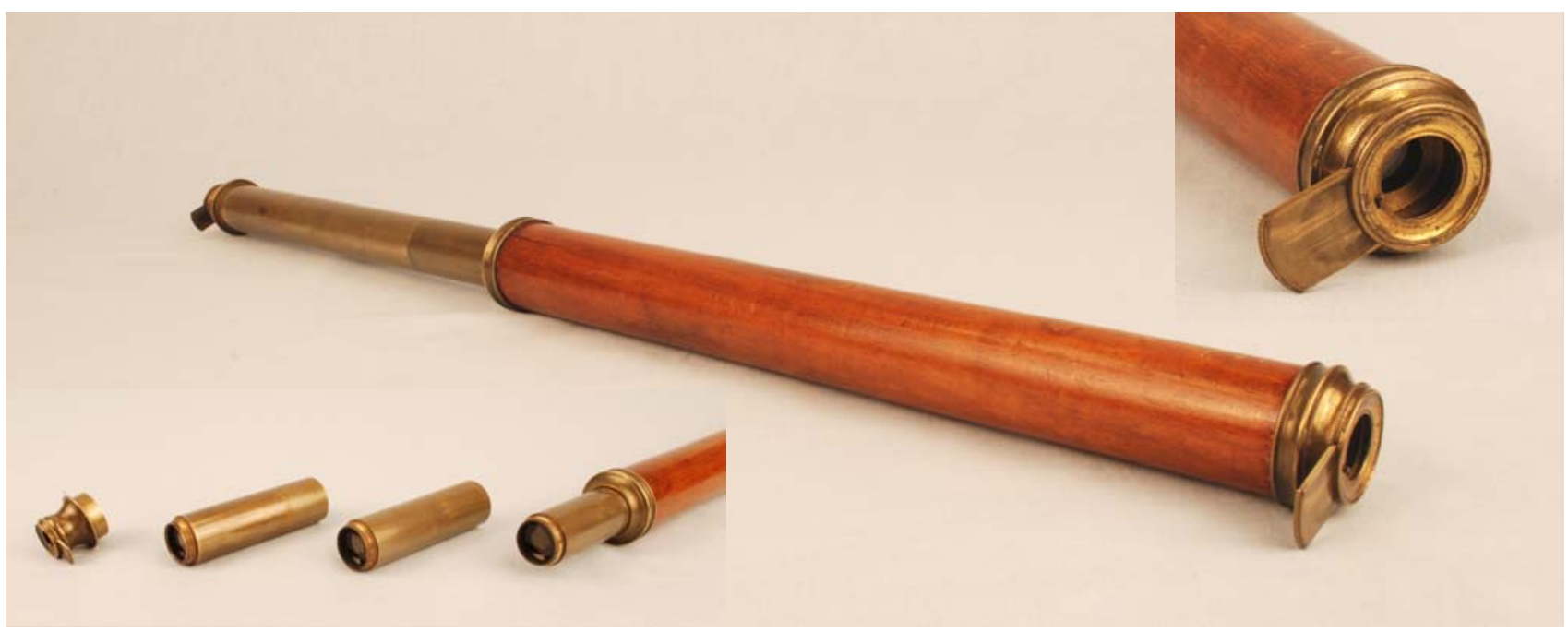

Figure 3. Single-draw pre-achromatic telescope with a wooden barrel and a Schyrle erecting system (unsigned, circa 1750, English). The telescope has an overall length of $570 \mathrm{~mm}$. The objective diameter is $23 \mathrm{~mm}$ with a $13 \mathrm{~mm}$ diameter aperture. Each segment of the draw contains one of the three lenses of the Schyrle erecting system.

\section{PRECISION BRASS TUBING}

The tubes that are used in a telescope must be rigid, durable and allow for the mounting of the optical elements. The draw tubes must slide easily to allow for focusing the telescope as well as to collapse into the main barrel to produce a more compact package. However once set in a position, the draws cannot slip. They must also maintain the alignment of the optics along the optical axis of the telescope; the telescope cannot bend at the junctions between draws.

Early telescopes, through the mid-1700s, were made of paper rolled into tubes with leather or vellum coverings. While the coverings provided some water resistance, this construction was not durable enough for extended use at sea or in other situations with damp or wet conditions. The lens cells and protective rings on draws were made of turned wood, horn and sometimes ivory. Later telescopes used brass fittings. Several examples from the early to mid-1700s are 
shown in Figure 5. The main barrel of the telescope was often highly decorated and the draws were sometimes decorated as well. These paper telescopes are very fragile.

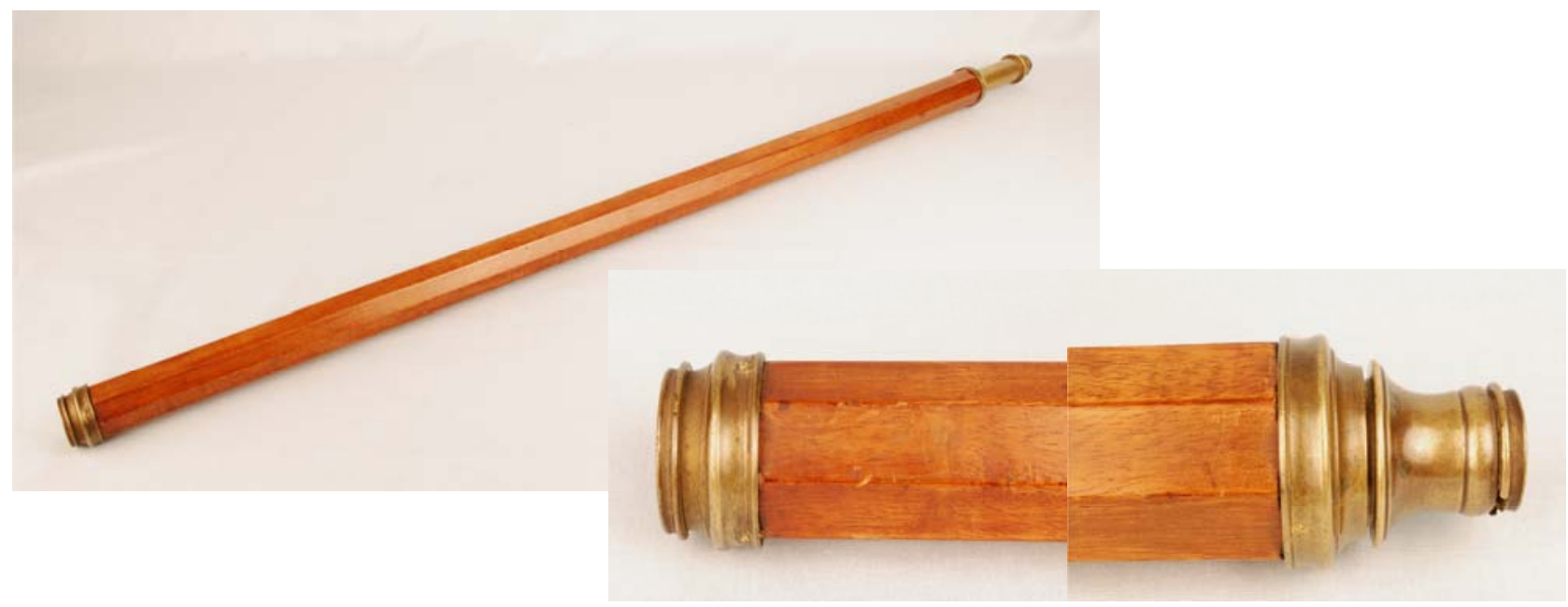

Figure 4. Reverse taper telescope (unsigned, circa 1750, English). The length of the telescope is $1090 \mathrm{~mm}$; the barrel diameter is $33 \mathrm{~mm}$ on the objective end and $42 \mathrm{~mm}$ on the eyepiece end.

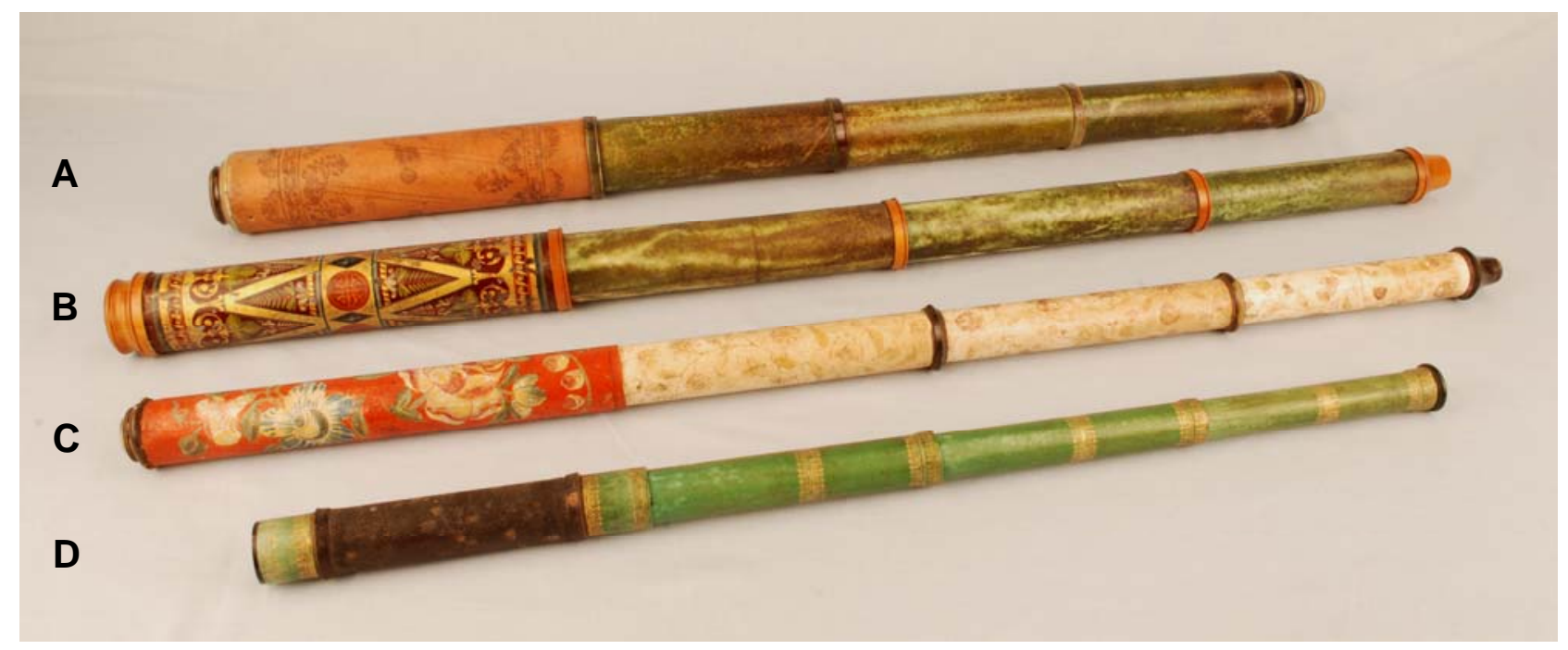

Figure 5. Paper telescopes from the early to mid-1700s: (A) Paper covered barrel and vellum covered draws, fittings made of horn. Length $840 \mathrm{~mm}$, barrel diameter 58mm (Leonardo Semitecolo, Venice); (B) Painted tin covered barrel and vellum covered draws, fittings made of wood. Length $810 \mathrm{~mm}$, barrel diameter $48 \mathrm{~mm}$ (unsigned, German); (C) Painted paper covered barrel and vellum covered draws, fittings made of horn. Length $820 \mathrm{~mm}$, barrel diameter 36mm (unsigned, Italian); (D) Leather covered barrel and vellum covered draws, fittings made of horn. Length 620 mm, barrel diameter 30mm (unsigned, French).

The advancements in materials for telescopes followed the Industrial Revolution in England. During this period, the transition was made from fragile instruments susceptible to damage, to durable long-lasting telescopes that performed and survived even in adverse conditions. In particular, the advent of precision brass tubing radically changed the construction of telescopes, as well as other instruments. Brass, which is an alloy of copper and zinc, is an ancient material, but is much more difficult to produce than bronze (alloy of copper and tin). High quality brass was not readily available until the 1700s [10]. Thin wall brass tubing was initially made by rolling or hammering brass into a thin sheet, 
bending it around a form and soldering the overlap. This type of tubing was used in musical instruments and for the main barrels of some optical instruments (including telescopes), but it is not appropriate for draws.

The drawing of wire, originating in the 1300s, was introduced into England in the late 1500s and was undoubtedly the precursor to drawing of precision tubes from metal. Brass tubes were first seen in microscopes in the 1740s and were commonly used in telescopes from around 1750 [11-12]. The brass was prepared for drawing by rolling a sheet of the metal into a cylinder that was wrapped around a mandrel that defines the inner diameter of the tube. The abutting edges of the cylinder were silver soldered together. The brass cylinder was then drawn with great force through a steel die. A series of dies were used to produce the desired wall thickness or outer diameter. Ductile flow produces precision tubing that is far superior to hammered sheet and hand-formed tubes. The smooth outer surface requires only a minimum of polishing.

At about the time brass was first used for draws, wood became the primary material for the main barrel of handheld telescopes. The main barrel of a telescope does not require the precision of the draws, but the barrel must be structurally rigid and durable. It must support the objective cell mounted on its front end and the draw coupling on the other end. Mahogany and fruitwood were the primary woods used. The use of wood minimized corrosion of the brass due to salt spray [11]. In addition, handling a wooden barrel was much more comfortable than brass for the user, especially in cold weather. Later, when brass was used for the main barrel of handheld telescopes, it was almost always covered with a wrap of leather or other material.

\subsection{Brass Draws}

In the early brass telescopes (circa 1750), there was a single draw which contained the erecting, field and eye lenses. In 1780, Dollond introduced telescopes which had multiple brass draws, usually three or four [3]. The draws in this design were made to very close tolerances. The multiple draws allowed excellent portability, as a 14" (355 mm) long telescope could be collapsed to a 5” (125 mm) in length and a 40" (1000 mm) long telescope could collapse to 10" (250 mm).

The early brass tube draws of the mid-1700s were comprised of three segments that screwed together. One of the three lenses in the Schyrle erecting system was mounted in each of the segments. The eye cup was attached to the final segment. Figure 6A shows an example of this system where the loose lenses are held in place by retaining rings. An improved mounting arrangement appeared around 1800 where a continuous draw tube is used and the lens elements are mounted in shorter tubes that nest inside the draw tube. The two erecting lenses are in one tube that provides the required separation, and the eye lens is mounted on a short tube that is either pushed in or screwed into the rear end of the eye draw. An example is shown in Figure 6B. Note that the lens elements were now contained in individual brass cells.

Similar mounting arrangements evolved for the Schyrle-Huygens erecting system or four-lens eyepiece. Starting in the mid to late 1700s, a three segment eyepiece draw was used. The two erecting lenses are mounted on each end of the forward segment. The field and eye lenses are contained in the other two segments (Figure 6C). By the mid-1800s, the mounting had changed to a continuous draw. Two inner tubes were used; one for the two erecting lenses and the other for the field and eye lenses (Figure 6D). Glare and field stops were incorporated into these inner tubes. The four lens Schyrle-Huygens erecting system design demonstrated its superiority and was the standard from the late 1700s through the early 1900s.

With the advent of multiple brass draws, couplings were devised which connected the draws, permitting them to slide smoothly into each other. They incorporated spring tabs that provided tension on each draw so the draws would remain in place whether extended or collapsed. The couplings were fashioned with raised knurled edges so the couplings could be unscrewed by hand and the draws taken apart for cleaning. These couplings were designed to screw into threads just inside the end of each draw. This design focused all lateral force from the draws on the threads, which sometime loosened or failed. Around 1800, Dollond devised a coupling which screwed into threads much deeper inside the draw. This configuration provides superior rigidity and strength because a second ring of contact occurs at the end of the draw with the shoulder of the coupling. This design was so advanced that it was used into the early 1900s. Examples of both types of coupling are shown in Figure 7. 
In very early single-draw telescopes, the draw was not retained and would pull out of the main barrel if extended too far. With multiple draw telescopes this is a significant issue as the several draws could come apart as the collapsed telescope is rapidly extended, and retention is a necessity. In fact, the multiple draws in paper telescopes are not retained, and great care must be exercised when extending these telescopes to their working length. Retention is provided by creating a shoulder on the front end of the draw that is larger than the draw diameter. When the draw is extended, this shoulder comes up against the inside or front edge of the coupling, stopping the motion. Various mechanisms were employed including a lens cell with a knurled shoulder, a ring soldered to the end of the draw, or a mechanical flaring of the draw tube itself. These types of retention mechanisms were also added to the junction between the barrel and the first draw (or single draw). Examples of these retention shoulders can be seen in Figure 7.

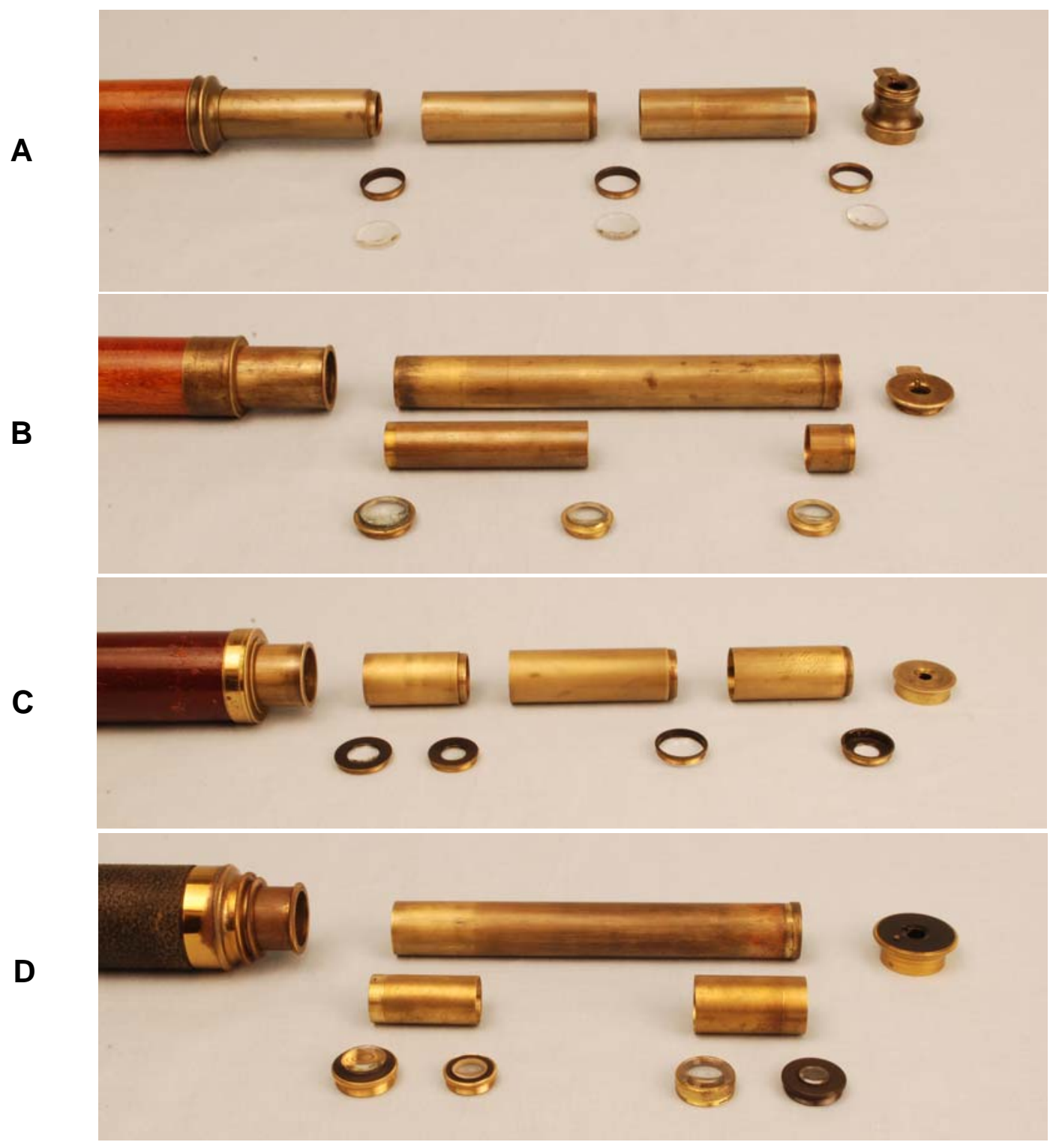

Figure 6. Eyepiece constructions: (A) Three-lens eyepiece with a segmented single draw (unsigned, English, mid-1700s); (B) Three-lens eyepiece with a continuous single draw (unsigned, English, circa 1800); (C) Four-lens eyepiece with a segmented eyepiece draw (Dollond, London, circa 1800); (D) Four-lens eyepiece with a continuous eyepiece draw (unsigned, French, late 1800s). 

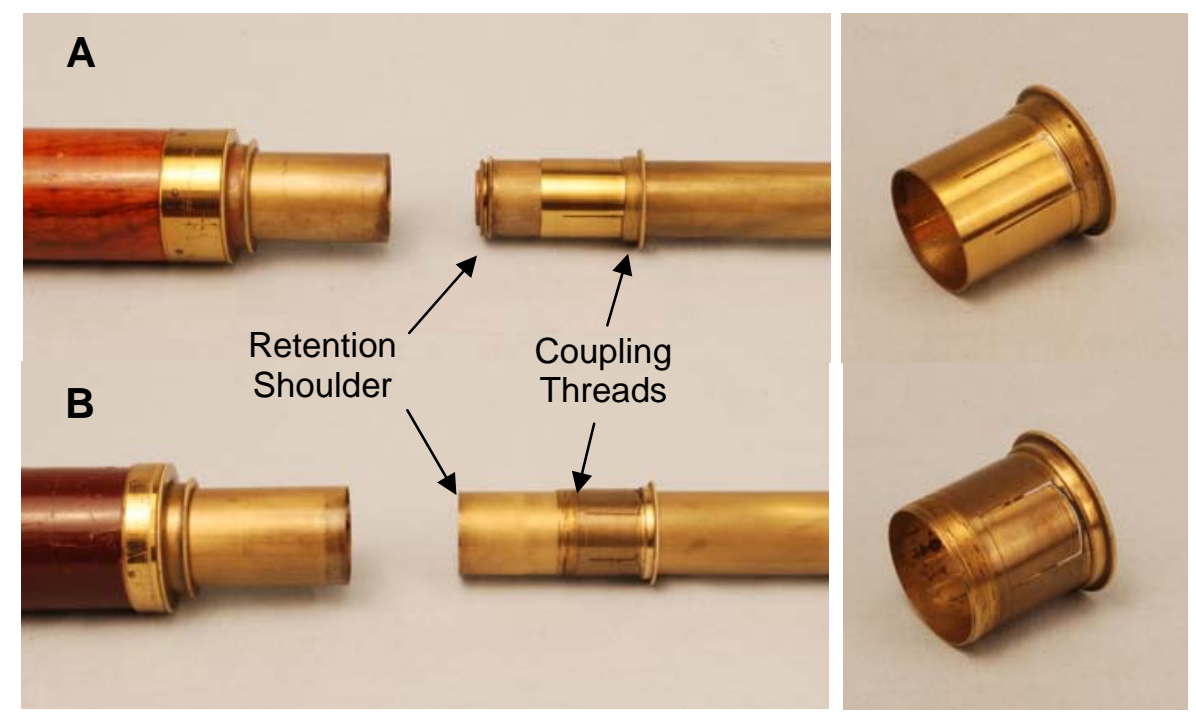

Figure 7. Couplings and retention: (A) Coupling screws into the end of the draw. Draw retention is provided by the knurled shoulder of lens cell (Utzschneider and Fraunhofer, Munich, early 1800s); (B) Coupling screws into threads deep inside the draw. Draw retention is provided by a ring on end of the draw (Dollond, London, circa 1800).

\subsection{Objective Lens Mounts}

The objective lens mounts on early paper telescopes were made of turned wood or horn, with the singlet lens retained in the cell with a threaded retaining ring. With these turned horn mounts, the retaining ring was often external or on the front of the telescope; the lens cell was glued to the front of the main barrel. When the transition to brass hardware on telescopes occurred, the lens cells were also made of brass. The early cells had an integral dust slide in front, with the lens inserted in the rear of the cell and held in place with a threaded cap. The cap had a built-in aperture with a small diameter to reduce the effective diameter of the objective lens for the purpose of reducing chromatic aberration.

After the achromatic doublet lens was introduced by Dollond, the two lenses were usually sealed together in a brass cell with a spun-over edge. Later, objectives were simply placed together in the cell, once again held in place with a retaining ring. It was not until well into the 1800s that the elements were cemented together with balsam. Examples of all of these lens mounts are shown in Figure 8.

One of the most advanced designs of an objective mount was made by Dollond, particularly for larger triplet achromatic objectives. The lens cell was made with a raised key on the inner diameter, parallel to the barrel. Each individual lens was notched to slide over this key and to maintain its orientation or clocking. The three lenses ware also marked with very small additional notches on their rear edge. There is one identification notch front lens, two notches on the middle lens and three notches the rear lens. This setup allowed the person assembling the lens (or reassembling the lens after cleaning) to know which lens went in which position, front to rear, as well as knowing which surface of each lens was to be oriented to the rear. An objective lens and mount of this type dating from about 1840 are shown in Figure 9 . The use of this exacting construction implies that the lens elements were clocked relative to one another to minimize astigmatism in the objective assembly. Individual spherical surfaces often have a small amount of cylindrical error from the polishing. Clocking the lenses allows the astigmatism in one element to be cancelled by the astigmatism in another element. While purely speculation on the part of the authors, the elements were likely tested and oriented by examining a star image produced by the objective itself with a microscope. The element orientations were adjusted to produce the best possible image. The testing would have been done prior to mounting the elements in the telescope. 


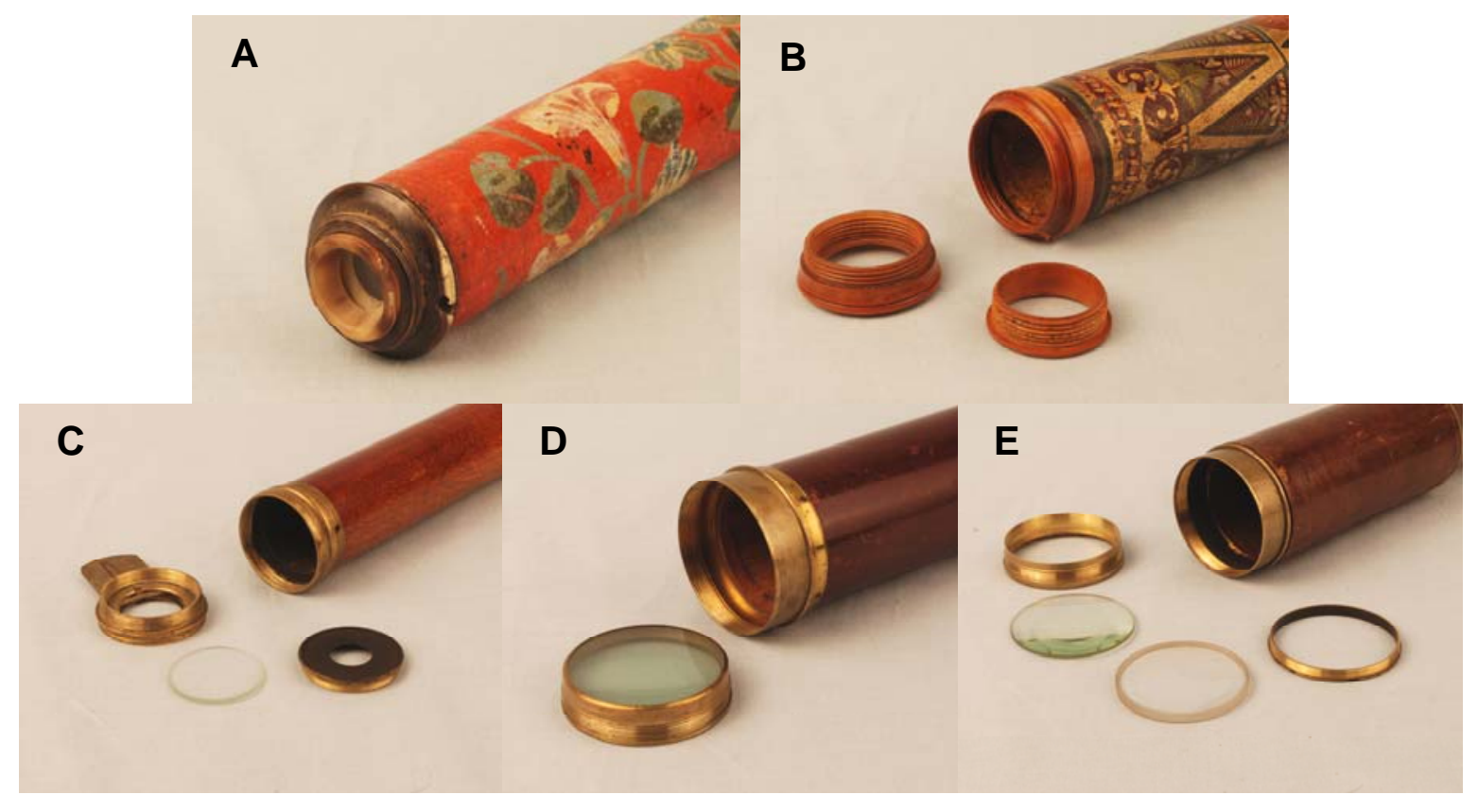

Figure 8. Objective lens mounting: (A) Lens is mounted in a turned horn cell with a horn retaining ring. The retaining ring is on the front of the lens cell (Leonardo Semitecolo, Venice, early to mid-1700s); (B) Lens is mounted in a turned wood cell with a wood retaining ring that screws into the rear of the cell (unsigned, German, early to mid-1700s); (C) Brass cell with an integral dust slide in front. The lens is held in place by a cap with a built-in aperture (unsigned, English, mid-1700s); (D) Lenses are sealed together in brass cell with a spun-over edge (Dollond, London, circa 1800); (E) Lenses are mounted in a brass cell with a retaining ring (Thomas Harris \& Son, London, mid-1800s).

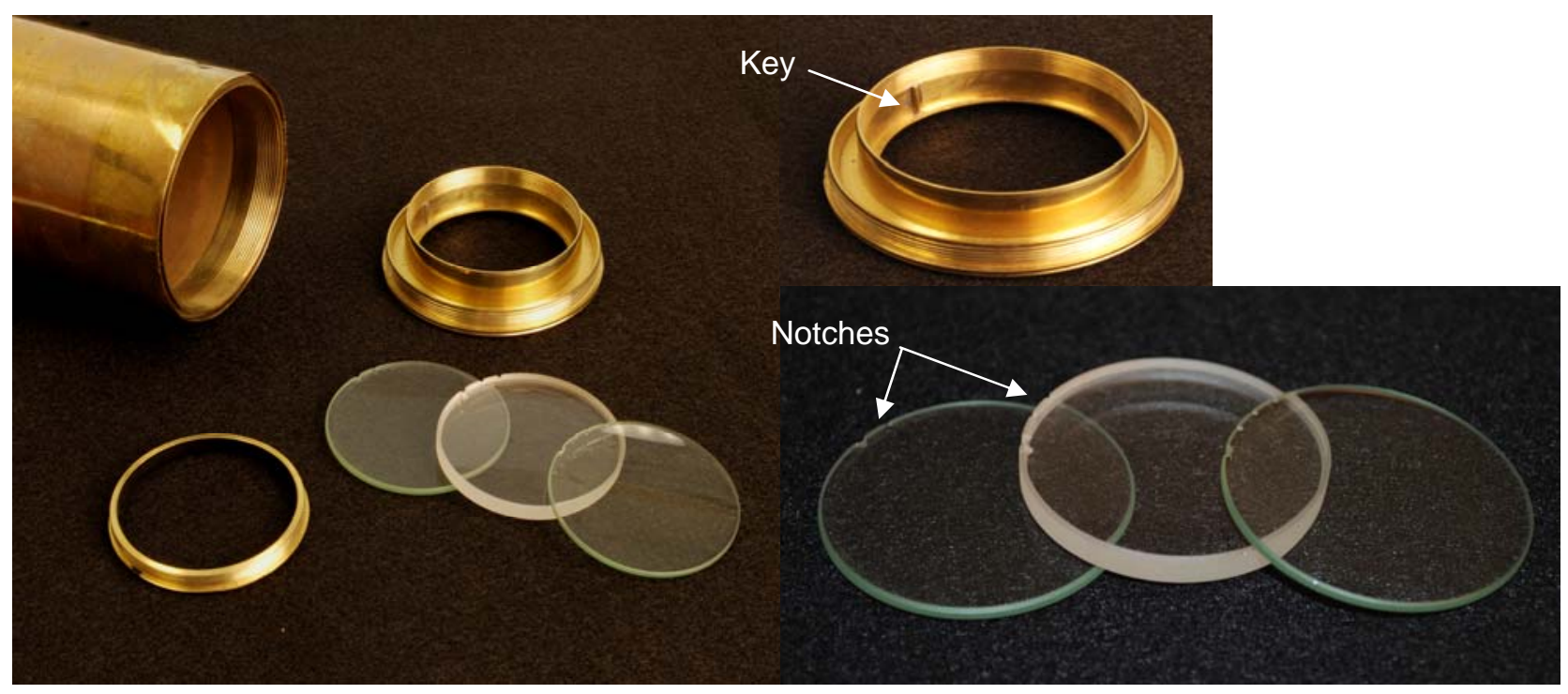

Figure 9. Objective lens mount for a triplet objective. The lens mount has a key to maintain the lens element orientations. The lenses are notched for the key and for identification. The element diameter is $43 \mathrm{~mm}$. Note the greenish cast of the early crown glass used for the first and third elements (Dollond, London, circa 1840). 


\section{GALILEAN BINOCULARS}

Early attempts to create binoculars using a pair of Galilean or Dutch telescopes date back to Lipperhey in 1608. Various other attempts were reported through the $18^{\text {th }}$ century, but the difficulties of alignment, focusing, and magnification match made reproducible manufacturing almost impossible. It was not until the early 1800s that Galilean binoculars were produced.

By the early 1700s, small Galilean telescopes, usually called spyglasses, prospect glasses, or opera telescopes, had become common. Initially, these handheld telescopes had a single draw and a small field of view. They usually had a magnifying power of 2-3X. By the end of the century, larger optics and achromatic objectives had allowed for increased field of view. Multiple draw spyglasses were also produced. A variety of spyglasses are shown in Figure 10.
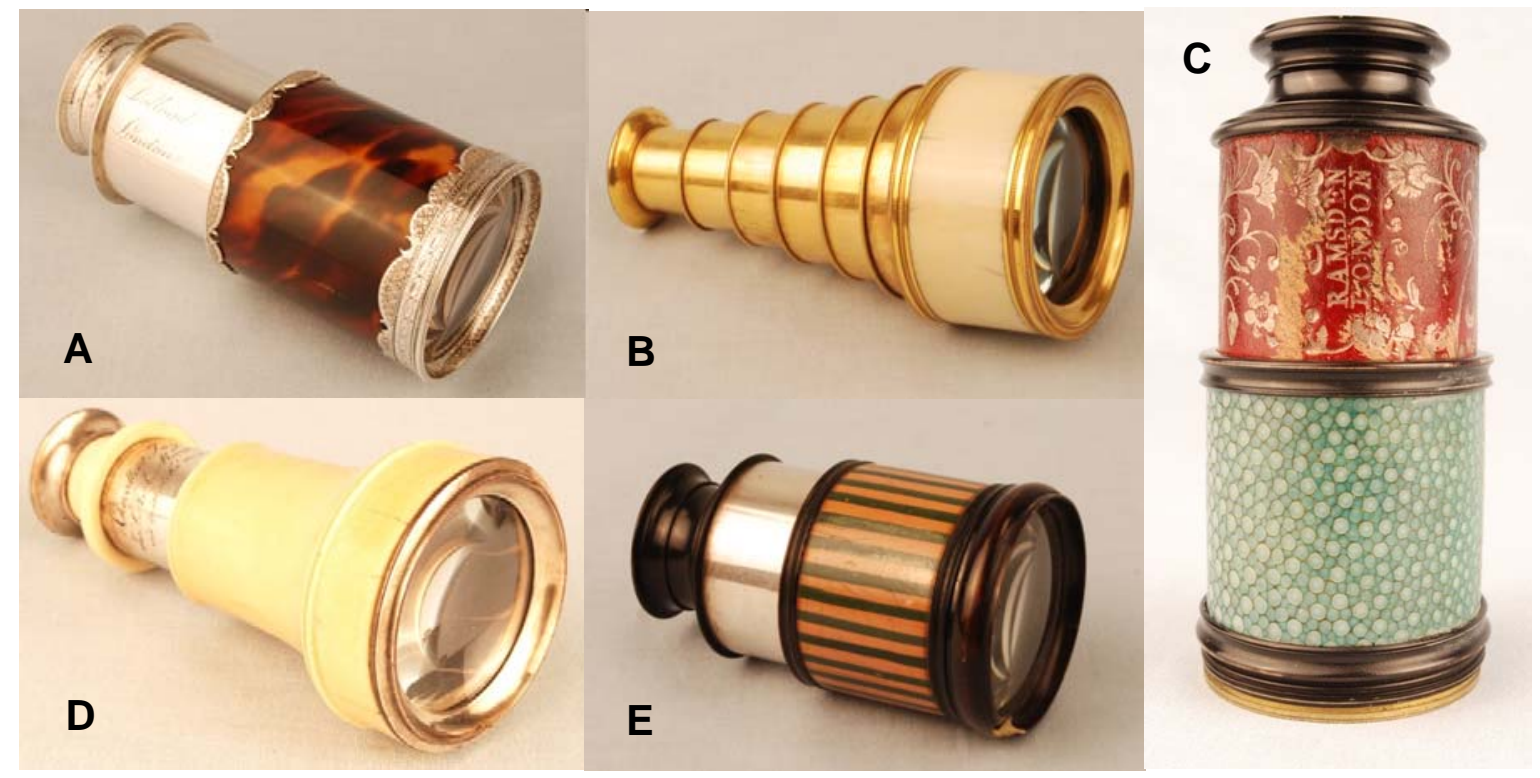

Figure 10. Galilean spyglasses: (A) Tooled silver and tortoise shell (Dollond, London); (B) Six-draw gilt brass with ivory (Dollond, London); (C) Cardboard draw with tooled leather, barrel covered with shagreen (Ramsden, London); (D) Ivory and silvered brass (Chevellier, Paris); (E) Ivory fittings with a silvered draw (Ramsden, London). All date from mid to late 1700s.

A major advance occurred in 1823 when J. F. Voigtländer patented the combination of two achromatic opera telescopes or spyglasses into a pair of opera glasses by using a frame with two bridges [13]. J. P. Lemiére of Paris improved upon this design by adding a third bridge between the two eye tubes. The focusing of the two telescopes was then coupled. One very early design was focused by turning one of the barrels to drive the motion of both eye draws (Figure 11). A later approach used a central focusing knob with a threaded screw. This basic design of opera glasses remains in use today. It is quite likely that there were earlier attempts to mount two spyglasses together with a single frame. In early implementations, the bridges run straight between the two telescopes. Later, the bridges were curved to allow "nose room” and provide user comfort. Examples of several types of bridges are shown in Figure 12.

In addition to their optical function, opera glasses became fashion accessories and as a result could be quite ornate. They were often covered in painted or patterned enamel or mother of pearl (sometimes covering the draw tubes). Several examples are shown in Figure 13. Optical performance also improved during the later 1800s as opera glasses were available with doublet objectives and doublet eye lenses for a total of eight lenses in the pair. While less common, opera glasses were also produced with triplet objectives and eye lenses. Larger diameter lenses were also used. This combination resulted in reduced chromatic aberration and wider field of view; however the magnification remained limited to about 3X. 


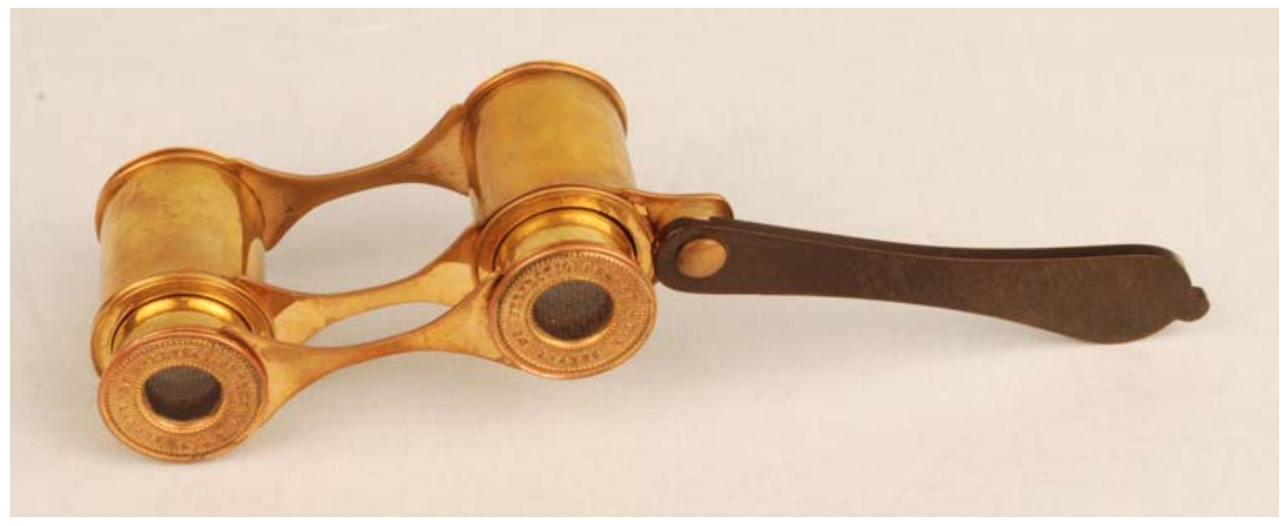

Figure 11. Lorgnette-style opera glasses with an early focusing mechanism. The left barrel is rotated to focus both telescopes, and the two eyepiece draws are attached to a third bridge. (French, early 1800s). The eyepiece inscription reads "Par Brevet de Perfectionnement," indicating that this design is "by patent of improvement."

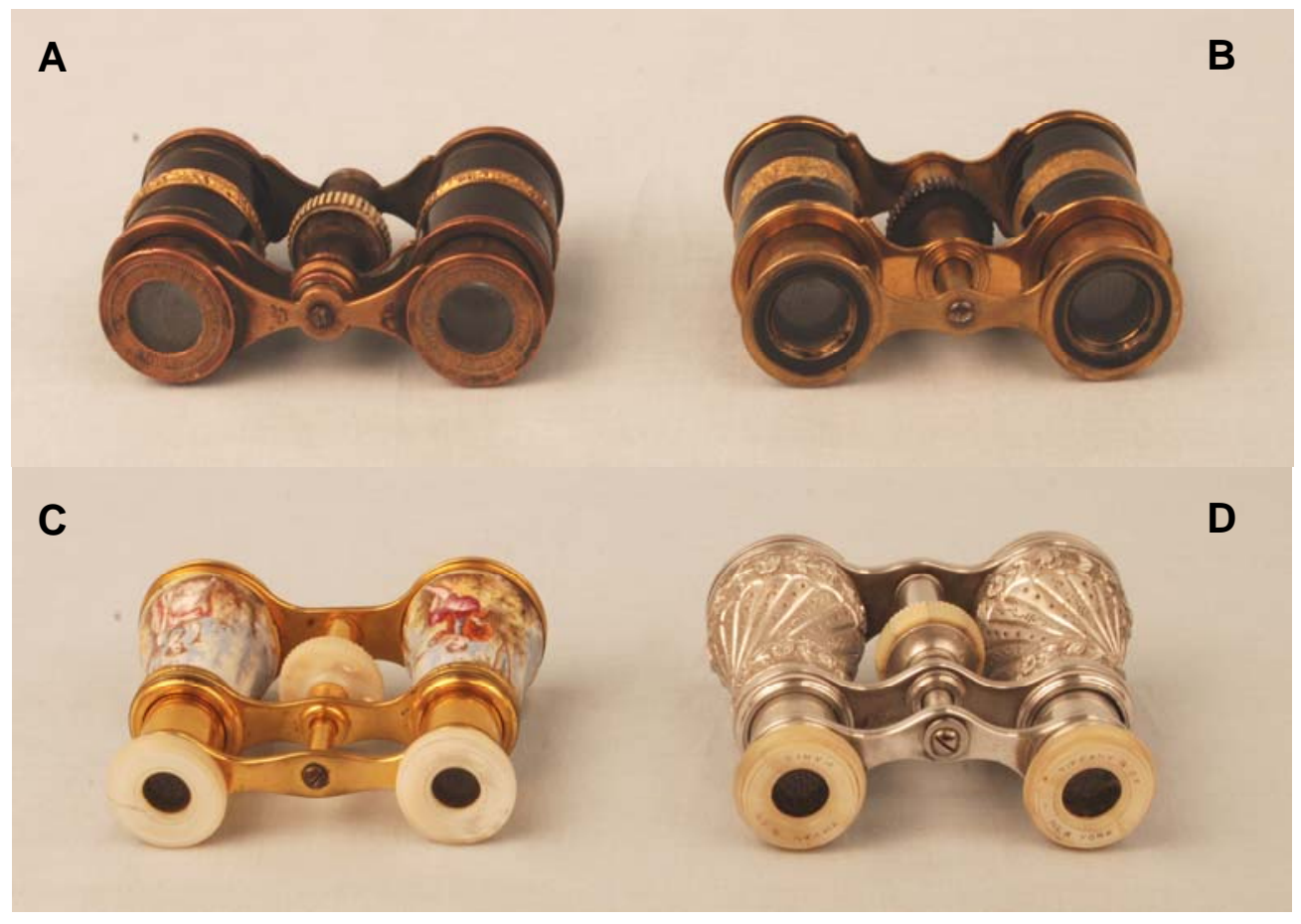

Figure 12. Opera glasses showing four varieties of bridging frames (French, mid to late 1800s): (A) X-shaped bridge (Par Brevet de Perfectionnement); (B) Straight bridge with flared ends (unsigned); (C) Straight bridge (unsigned); (D) Curved bridge (Tiffany and Co., Paris). 


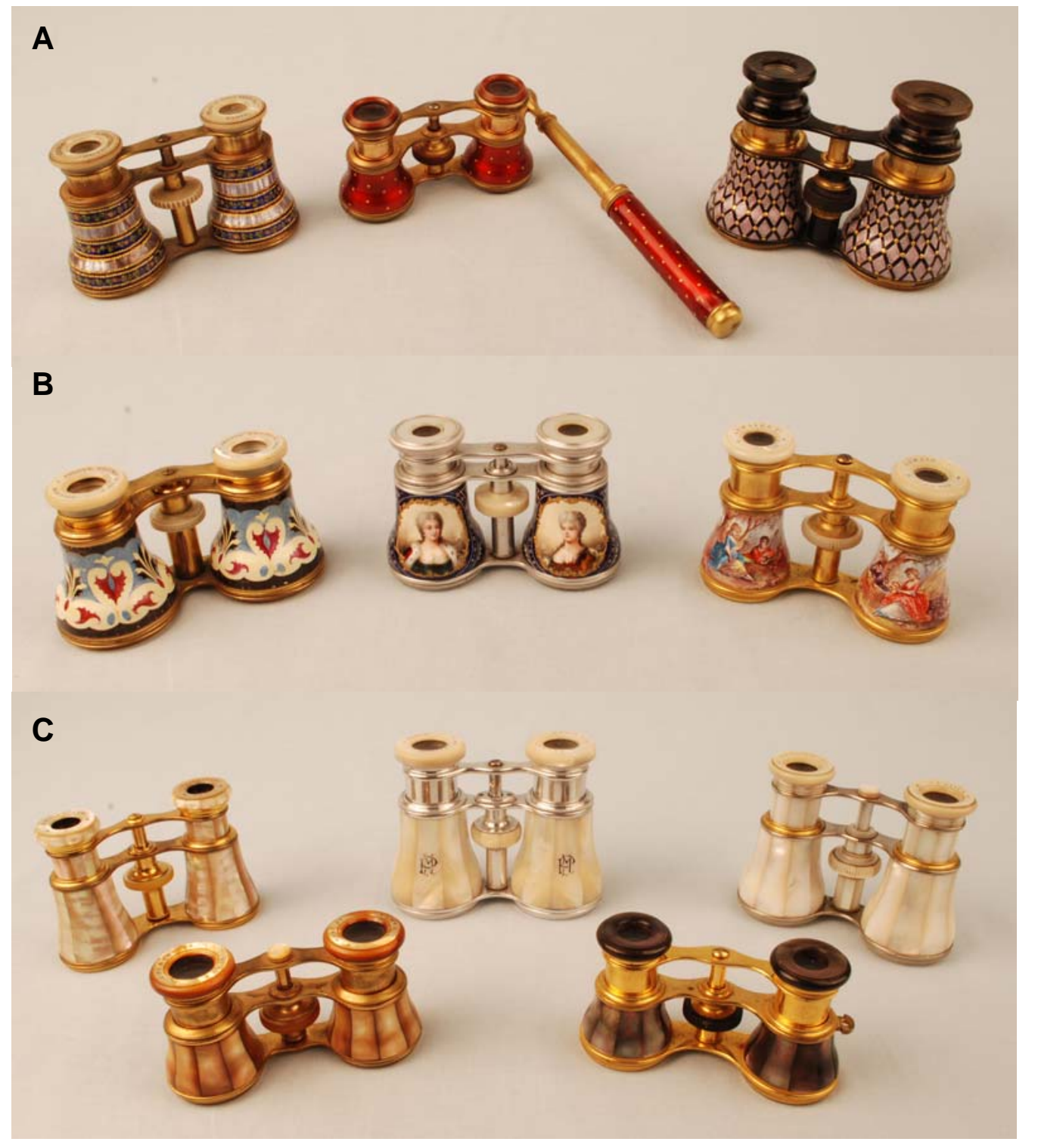

Figure 13. Decorative opera glasses (French, mid to late 1800s): (A) Patterned enamel; (B) Painted enamel with designs, portraits and scenes; (C) Mother of pearl.

Larger Galilean binoculars with somewhat higher magnifying power (sometimes called field glasses) were developed by the mid-1800s (Figure 14). The maximum magnifying power was about 5-6X, but the field of view decreased with increased magnification. These field glasses were widely used for military and other applications through WWI. Because of their increased size, weight could be a significant issue, and therefore field glasses took advantage of aluminum when it became available in the late 1800s. Both opera glasses and field glasses are relatively simple optical systems, but they suffer from the low magnification and limited field of view inherent to Galilean telescopes. 


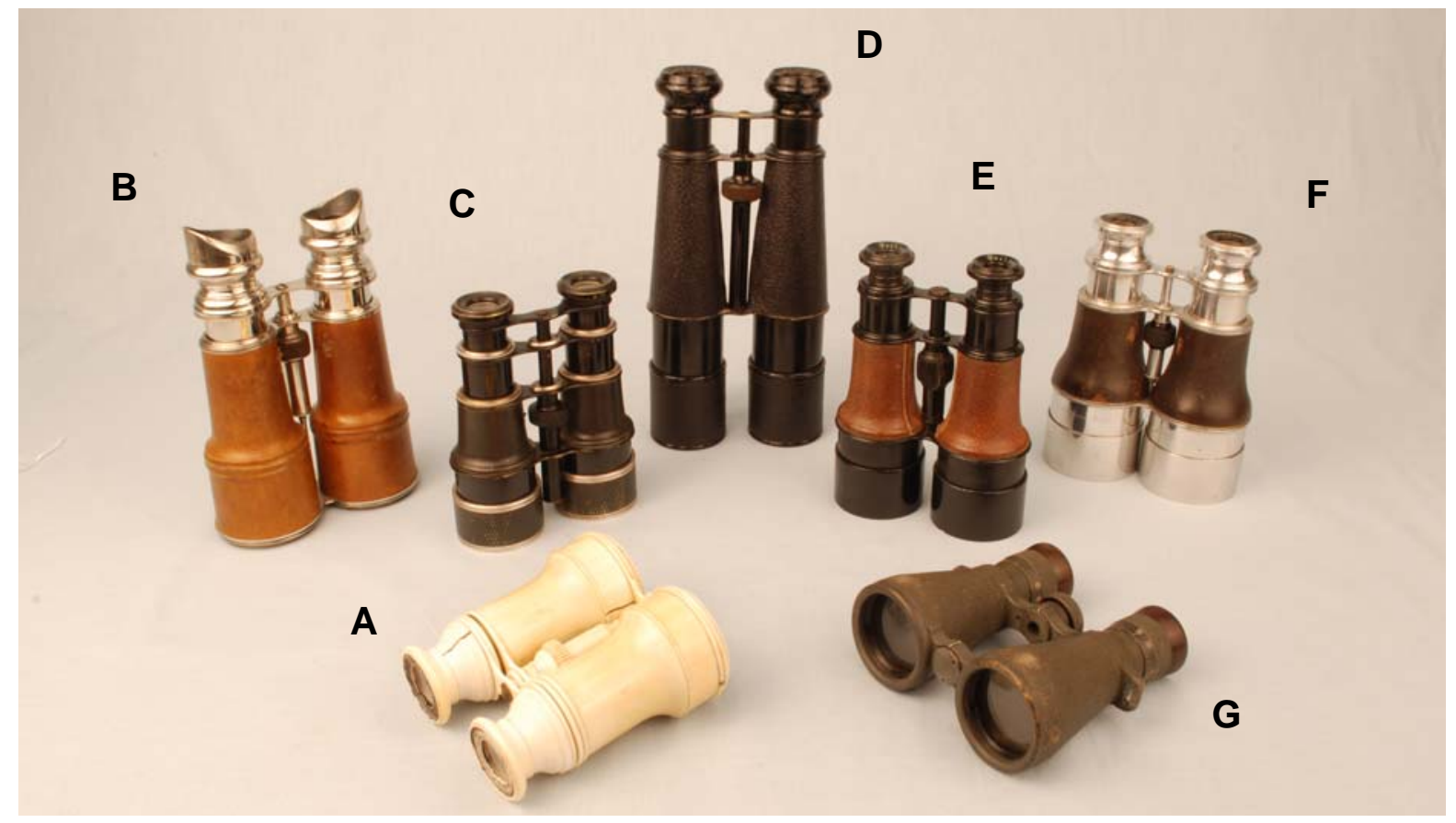

Figure 14. Field Glasses (mid-1800s through early 1900s): (A) Ivory (unsigned, French); (B) Stylish lowpower with a leather covering (Marquise, Paris); (C) Rare two-draw (unsigned, French); (D) Long, painted brass (Chevalier, Paris); (E) Painted brass with leather (Dollond, London); (F) Aluminum with leather (C. W. Dixey, London); (E) German military field glasses (fernglas) dating from WWI (Carl Zeiss, Jena).

\section{TWIN TELESCOPES}

An alternative solution for obtaining an erect image in a pair of binoculars was to use two Keplerian telescopes with Schyrle erecting lenses (terrestrial telescopes). This twin telescope configuration tended to be relatively long due to the number of optical elements, but nonetheless there were a number of early attempts to construct binoculars of this form. A surviving example was built in 1675 by Chérubin d'Orleans [14]. At over a meter in length, it must have been very unwieldy to use. Binoculars of this form suffered from the same problems as the early attempts at Galilean binoculars: alignment, magnification match and focusing. Because of the longer length, higher magnification and more complicated optical systems, the issues are more severe with twin telescope binoculars than Galilean binoculars.

Twin telescope binoculars have the advantage of the larger field of view of a Keplerian telescope. By the mid-1800s, mechanical and optical technology had advanced enough to allow twin telescope binoculars to be produced. An early example from G. \& S. Merz dates from about the 1860s (Figure 15). By the last quarter of the $19^{\text {th }}$ century, twin telescopes had evolved to very sophisticated optical systems. In some models, the lens system and the mechanical mounting were miniaturized so that they could be produced with a length of less than $160 \mathrm{~mm}$. These small twin telescope binoculars had objective lenses with aperture diameters of 10-12 mm, and they collapsed for storage to under $120 \mathrm{~mm}$. A variety of twin telescope binoculars are shown in Figure 16.

The twin telescopes of the late 1800s were a tour de force of optical and mechanical fabrication. However, the life of this technology was abruptly ended by the advent of prism binoculars in the 1890s. Twin telescopes would be considered difficult to fabricate even today. In the mid-1800s, the problem of adjusting binoculars for interpupillary spacing was solved by allowing the bridge between the two telescopes to bend at a hinge. 


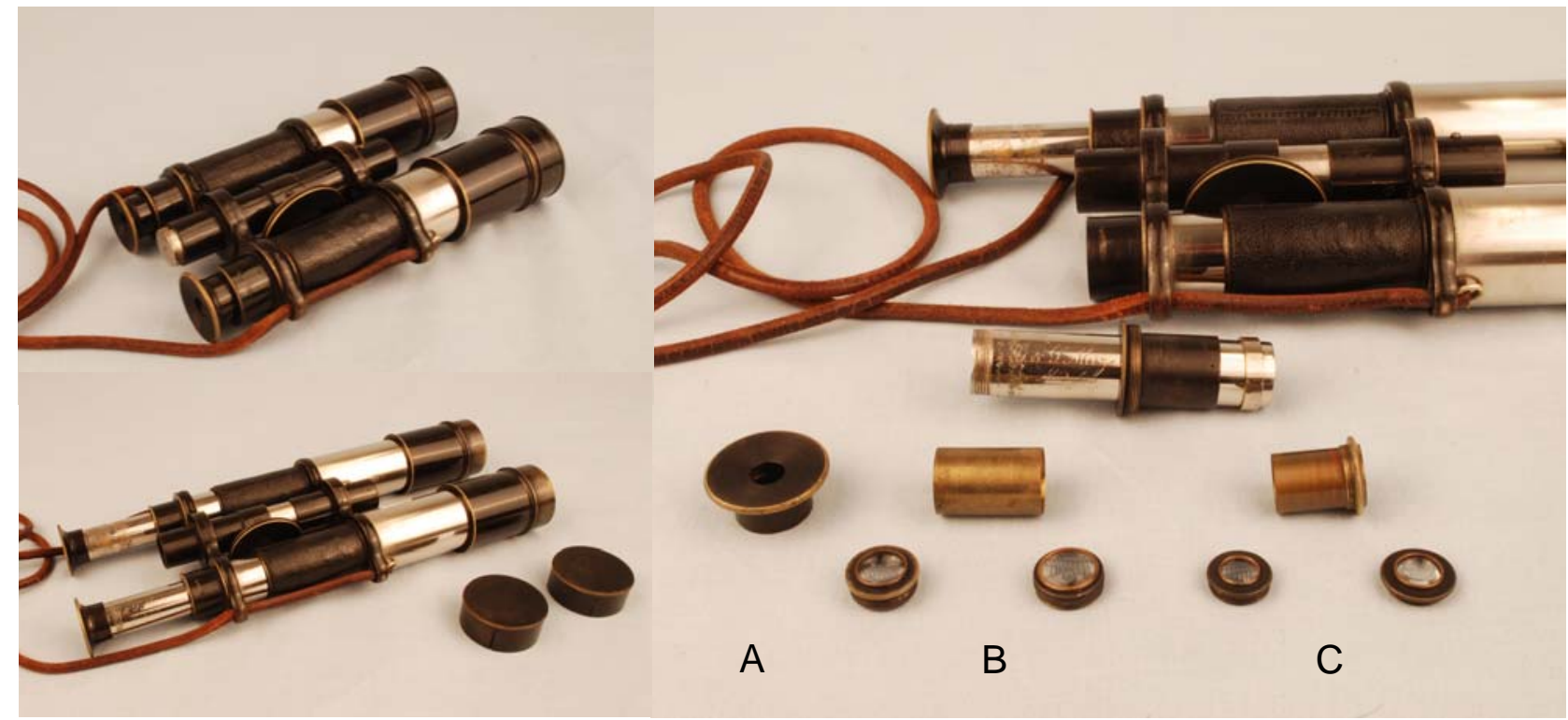

Figure 15. G. \& S. Merz twin telescope binoculars (Munich, circa 1860). The binoculars are shown both in their collapsed form and as extended for use. Focusing is done by means of a rack and pinion using the large knob. The binoculars bend along a central hinge to adjust for interpupillary spacing. An exploded view of the components and mounts in one of the eye draws is shown: (A) eye cup; (B) erecting couplet lenses and mounting tube; (C) field and eye lenses and mounting tube. The nickel-plated draw receives both of the smaller mounting tubes to provide the required element spacings.

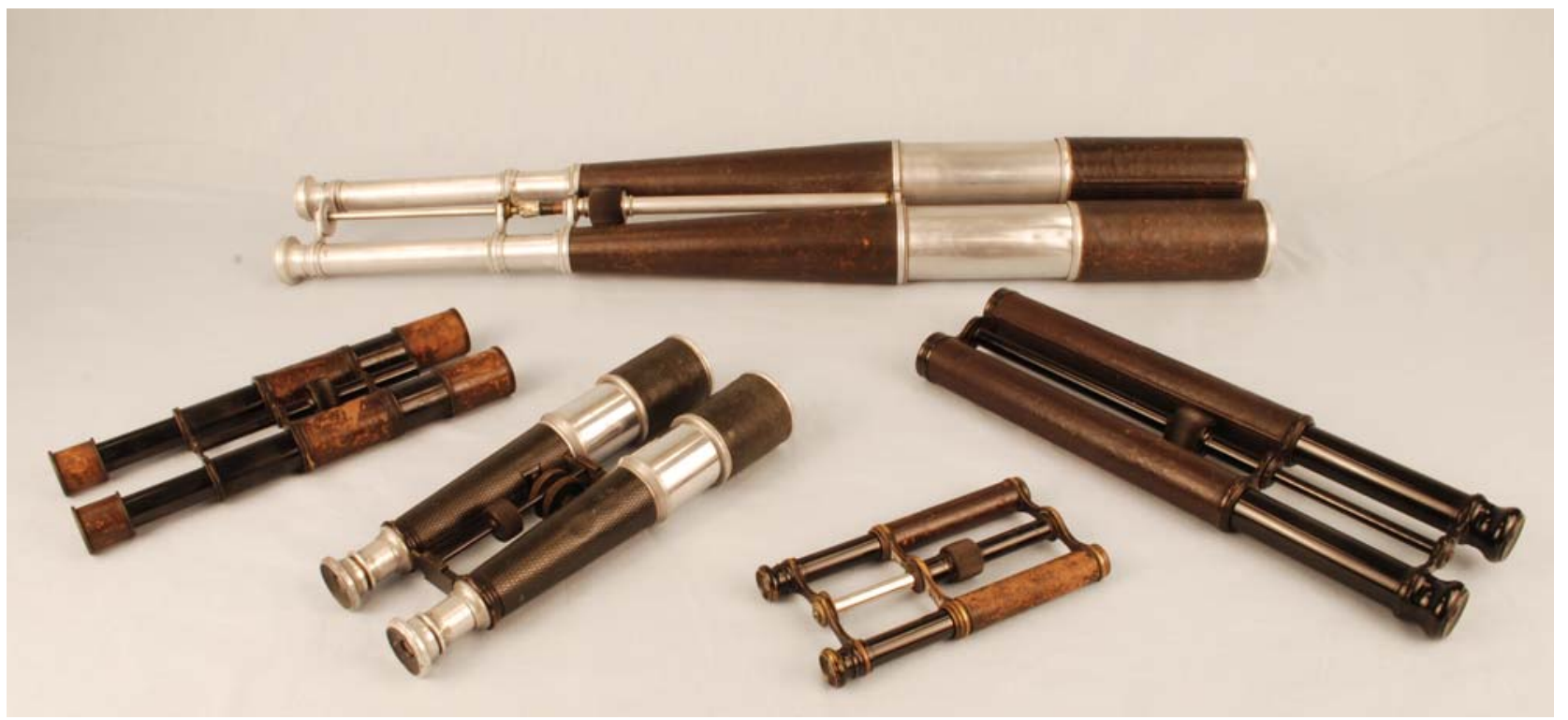

Figure 16. Various twin telescopes dating from the late 1800s. Two of the twin telescopes shown are aluminum and three are brass. The large telescope has a length of $750 \mathrm{~mm}$ with its sunshades extended. The magnifying powers range from about $5 \mathrm{X}$ to $20 \mathrm{X}$. 


\section{PRISM BINOCULARS}

The technical advance that led to the modern design of binoculars was the invention of image erecting prisms in 1854 by Ignatio Porro [15-16]. The Porro prism system uses two right-angle prisms and a total of four internal reflections. With this prism system, the eyepieces are laterally displaced from the objective lenses. The Porro prism system allowed the image in a Keplerian telescope to be erect without the need for erecting lenses. This greatly shortened the overall length of the system and allowed for larger diameter objective lenses. The result is the modern embodiment of prism binoculars consisting of an objective lens, image erecting prisms and a two-element eyepiece with a field lens and an eye lens.

Attempts to fabricate prism binoculars after the invention of the Porro prism system failed primarily due to poor glass quality. The folded optical path through a Porro prism system can be $60 \mathrm{~mm}$ or more. Even a small amount of inhomogeneity or stria in the glass can destroy the image quality of the binoculars.

The association of Carl Zeiss with the glass maker Otto Schott resulted in the production of the high quality prisms that were essential for successful Porro prism binoculars. Ernst Abbe provided the optical design of these binoculars. These high-performance modern binoculars were first sold in 1894. An early pair of Zeiss 6X15 Porro prism binoculars with serial number 306 and dating from 1895 is shown in Figure 17. Note that in these binoculars, focusing was performed by individually adjusting both eyepieces. The prism mount consists of a recess machined into the cast aluminum body of the binoculars. Each Porro prism is held in place by the prism cover or end plate and a thin piece of cork on the prism apex. This same arrangement was used on both ends of the body of the binoculars so that there is a large separation between the two Porro prisms. In modern binoculars, the two Porro prisms are mounted in contact or in close proximity near the eyepiece to allow for larger diameter objectives. The dimensions of the hypotenuse of this early Zeiss Porro prism are $15 \times 32 \mathrm{~mm}$. Based upon Abbe refractometer measurements, the prism is a crown glass with an index of refraction of 1.513 and an Abbe number of about 63.

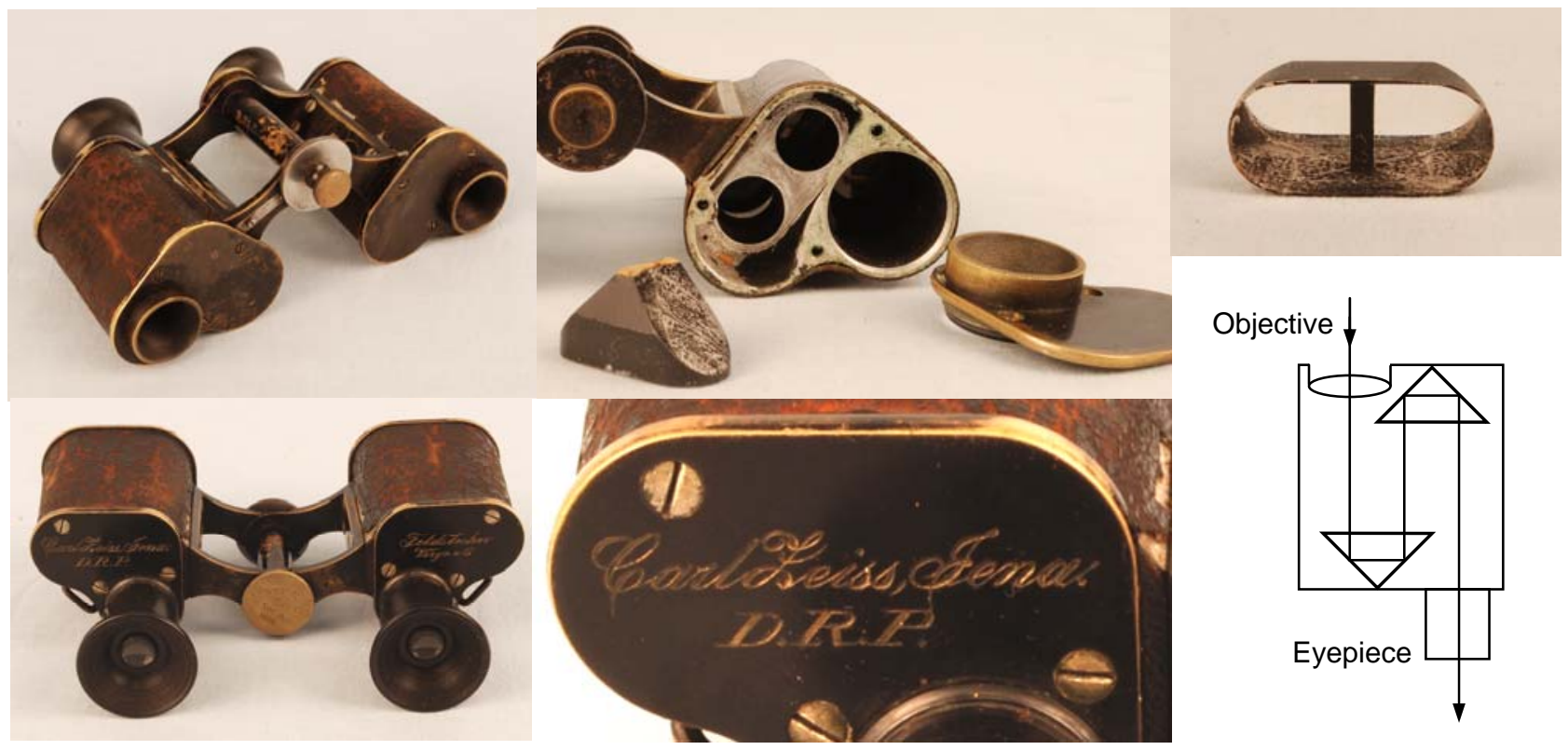

Figure 17. Zeiss 6 X15 binoculars with serial number 306 (1895). The script inscription reads "Carl Zeiss, Jena D.R.P." and "Feldstecher Vergr $=6$ ". The now-familiar Zeiss lens logo was first used in 1904. Removing the prism cover and the objective lens shows the prism mount and a Porro prism for a pair of 8X20 binoculars of the same era (No. 4976; 1897). The diagram shows the arrangement of the prisms in the housing. Of course, both prisms are actually rotated by 45 deg out of the plane. In this $8 \mathrm{X}$ pair, the prism separation is approximately $30 \mathrm{~mm}$; the separation is approximately $20 \mathrm{~mm}$ in the $6 \mathrm{X}$ binoculars as the prism body is shorter. 
In 1897, erecting prism systems incorporating roof surfaces were introduced into binoculars [17]. They were first used in a penta-prism configuration by the firm of Hensoldt in Wetzlar, Germany, and a more compact arrangement made use of a Leman (or Sprenger-Leman) prism. A later example of Leman-prism binoculars is shown in Figure 18. The AbbeKöenig prism appears in the very early 1900s, and with this prism, image erection is obtained without a displacement of the optical axis (Figure 19). An asymmetrical version allows for an increased separation of the objective lenses. The Abbe-Köenig prism is the precursor of the Pechan-roof prism (also know as a Schmidt-Pechan prism) used in modern roof-prism binoculars. By 1907, Zeiss was also producing binoculars incorporating roof surfaces. Another variation of roof prisms is the Möller prism that produces six internal reflections (Figure 20). Along with the Leman prism, this prism allows for the design of a flat pair of prism binoculars where the required out-of-plane reflections are obtained from the roof surface. In both cases, the eyepieces are laterally displaced from the objectives. Neither of these prisms is in common use today.
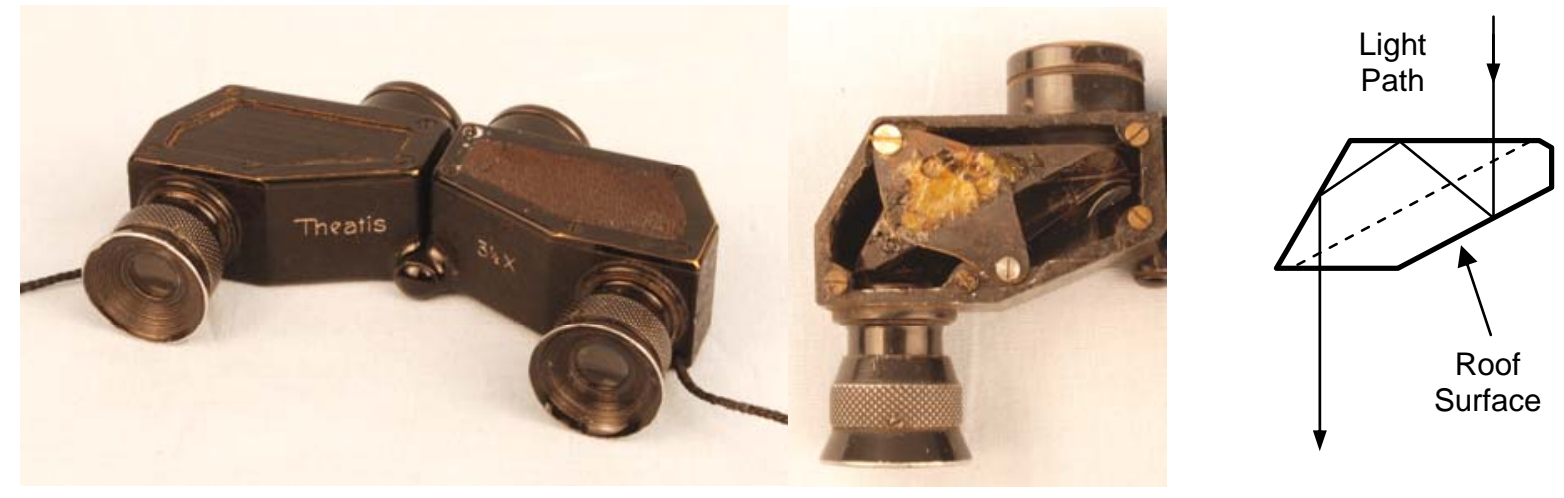

Figure 18. Leman prism binoculars (Theatis 31ำX; J.D. Möller, Wedel, Germany, late 1920s). Four reflections are obtained with this compact image-erection prism.
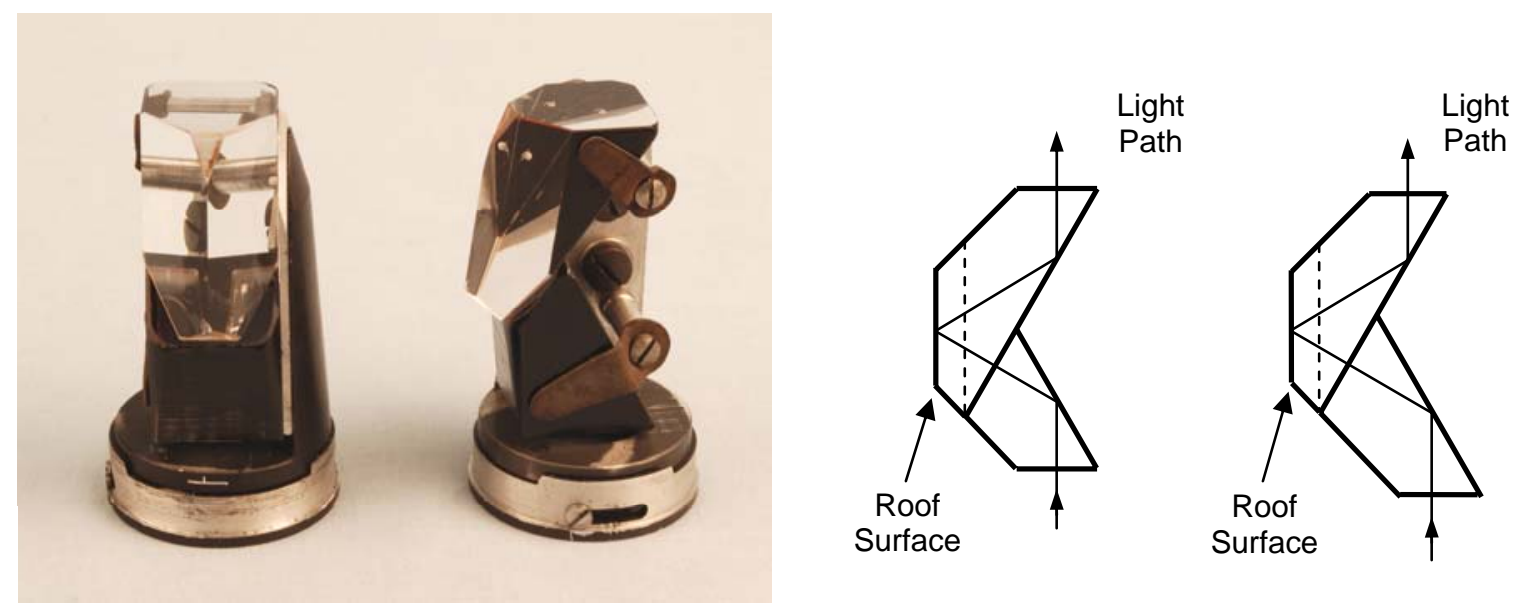

Figure 19. Abbe-Köenig prisms (Hensoldt, Wetzlar, Germany, early 1900s) The two prism components are mounted in a frame with a small air gap. Schematic representations show the light path with four reflections that produces image erection without a displacement of the optical axis. An asymmetric variation allows for a small displacement of the axis to permit increased separation of the binocular objective lenses. 

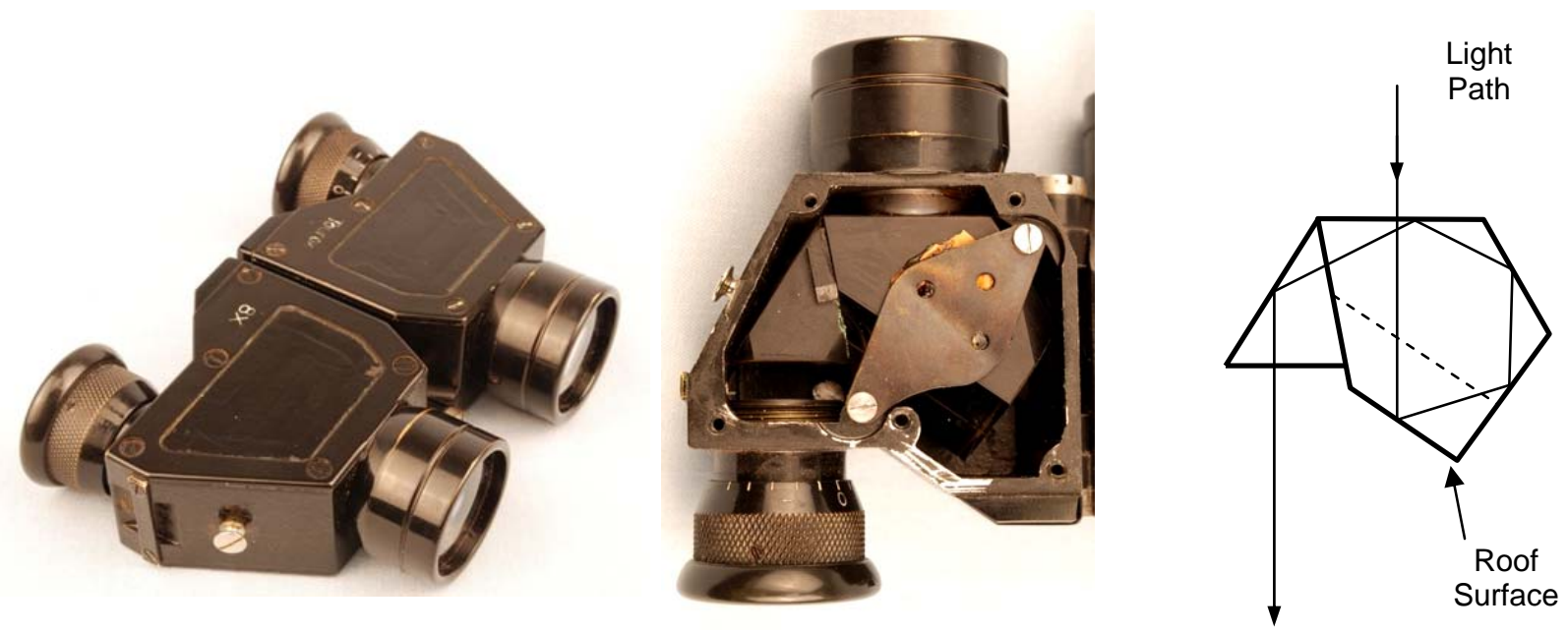

Figure 20. Möller prism binoculars (Tourox 8X; J.D. Möller, Wedel, Germany, mid-1920s). This imageerection prism system consists of two prisms that are bonded together and held in place by a spring clip. A total of six reflections are obtained.

\section{CONCLUSIONS}

This paper has highlighted some of the important steps in the development of handheld telescopes and binoculars. While none of the information presented in this paper is actually new, the evolution of telescopes and binoculars was treated from an engineering perspective. The story certainly starts with optical configurations, but the development is dependent on advances in mechanical design, manufacturing technology, materials and optical glass. The importance of the availability of precision brass tubing can not be understated. It is easy to think of binoculars as just two telescopes, but the requirements for binoculars are much more complicated than for telescopes. As a result, terrestrial handheld refracting telescopes were able to reach their modern design form in a little over a century, while it took binoculars nearly three centuries.

Numerous variations in design have occurred over the years that the instruments described in this paper were produced, and it is not possible to cover all variations in an overview paper such as this. The examples discussed are intended to show the more prominent designs as well as to identify technology trends and innovations. Significant effort has been made to be as accurate as possible in the description and dating of the instruments presented in this paper, however many of these items are difficult to accurately characterize and/or date.

The Museum of Optics of the College of Optical Sciences at the University of Arizona can be viewed on-line at www.optics.arizona.edu/museum.

\section{REFERENCES}

[1] A. Van Helden, “The Invention of the Telescope,” Trans of the American Philosophical Society, New Series, 67(4), 1-67 (1977); reprinted 2008.

[2] J. E. Greivenkamp and D. Steed, “The 300-Year Quest for Binoculars,” in International Optical Design Conference 2010, Proc. SPIE-OSA, 7652, 76520J (2010).

[3] Reginald J. Cheetham, Old Telescopes, A Samedie Book, Lancashire (1997).

[4] T. H. Court and M. Von Rohr, "A History of the Development of the Telescope from About 1675 to 1830 Based on Documents in the Court Collection,” Trans. Optical Society, 30, 207-260 (1929). 
[5] Richard Dunn, The Telescope - A Short History, National Maritime Museum, Greenwich (2009).

[6] P. Louwman, “Christian Huygens and His Telescopes,” Proc. of the International Conference: Titan from Discovery to Encounter, ESA, SP-1278, 103-114, ESTEC, Noordwijk, The Netherlands (2004).

[7] M. E. Rudd, “Chromatic Aberration of Eyepieces in Early Telescopes,” Annals of Science, 64, 1-18 (2007).

[8] R. Willach, “The Development of Telescope Optics in the Middle of the Seventeenth Century,” Annals of Science, 58, 381-398 (2001).

[9] H. L. King, The History of the Telescope, 144-175, Dover, New York (1955).

[10] J. Day, “Copper, Zinc and Brass Production,” in The Industrial Revolution in Metals, J. Day and R. F. Tylecote, Eds., 131-199, The Institute of Metals, London (1991).

[11] R. S. Clay and T. H. Court, “English Instrument Making in the $18^{\text {th }}$ Century,” Trans. Newcomen Society, 16, 45-54 (1935-36).

[12] A. Mills, “The Manufacture of Precision Brass Tubing,” Bul. of the Scientific Instrument Society, 27, 10-15 (1990).

[13] M. Von Rohr, "Contributions to the History of English Opticians in the First Half of the Nineteenth Century (with Special Reference to Spectacle History),” Trans. Optical Society, 28, 117-148 (1926-27).

[14] A. Van Helden, Catalogue of Early Telescopes, Istituto e Museo di Storia Della Scienze, Firenze (1999).

[15] W. R. Warner, “The How and Why of the Porro Prism Field-Glass,” Trans. Am. Soc. of Mechanical Engineers, 23, 313-326 (1902).

[16] H. Volkmann, “Ernst Abbe and His Work,” Appl. Opt. 5, 1720-1731 (1966).

[17] R. Riekher, Fernrohre und ihre Meister, Verlag Technik, Berlin (1990).

A useful collection of on-line resources associated with the history of binoculars and telescopes is maintained by Peter Abrahams. It can be viewed at www.europa.com/ telscope. 